\title{
Biosynthesis, Extraction and Characterization of Extracellular Polymeric Substances (EPSs) from Aspergillus clavatus
}

\author{
Shimaa S Hussien* \\ Assistant Professor of Microbiology, Ore Processing Department, Nuclear Materials Authority, Cairo, Egypt
}

\begin{abstract}
Six fungal strains were isolated from El-Sella ore material (Fusarium solani, Penicillium purpurogenum, Aspergillus niger, Aspergillus clavatus, Cladosporium herbarum and Epicoccum nigrum), and screened for exopolysaccharides (EPSs) production. In this study, the most promising fungus producing exopolysaccharides (EPSs) was A. clavatus which was identified according to microscopic morphological feature. The effects of environmental parameters on exopolysaccharides production by $A$. clavatus were investigated. The optimum medium composition was found to be at $\mathrm{pH} \mathrm{5}$, glucose and peptone were the best nitrogen and carbon sources. Also, $1 \mathrm{~cm}$ disc of inoculum size at $30{ }^{\circ} \mathrm{C}$ was incubated for 9 days using shaking condition $(150 \mathrm{rpm})$ were the other optimal conditions. Under these optimum conditions, the predicted yield of EPSs was up to $885.3 \mathrm{mg} / \mathrm{L}$. Further, the structure of exopolysaccachrides was confirmed by FT-IR, ${ }^{1} \mathrm{H},{ }^{13} \mathrm{C}$ NMR, HPLC and mass spectroscopy were employed to characterize the EPSs extracted from $A$. clavatus. Based on this spectroscopy results, the exopolysaccharides produced by $A$. clavatus was $\alpha$-D-glucopyranosyl units. The HPLC chromatography showed that the EPSs consist of one peak; glucose.
\end{abstract}

Keywords

Aspergillus clavatus, EPSs production, Physiological conditions, Characterization, $\alpha$-D-glucopyranosyl unit

\section{Introduction}

Microorganisms can synthesis different type of polymeric substances (PSs) according to their location in the cell, structure, sugar composition, type of bonds between monomers, and systematic affinity. The extracellular polymeric substances (EPSs) are a complex mixture of macromolecular polyelectrolytes including polysaccharides, proteins, nucleic acids [1], amino acids, lipids or humic substances [2]. Fungal PSs are classified into different groups according to systematic affinity, structure (linear and branched), sugar composition (homo- and heteropolysaccharides), type of bonds between the monomers (b-(1-3), b-(1-6), and $\alpha-(1-3))$ and their location in the cell (cell wall PSs, exo PSs, and endo PSs). Ascomycota and Basidiomycota EPSs are mainly heteropolysaccharides but in the case of homopolysaccharides glucose is their only monomer. Exopolysaccharides are most frequently studied fungal PSs but their definition, classification, and origin are still not clear and should be explained. EPSs are rather defined by the separation/extraction method used than by theoretical consideration of the composition of the cell wall and macromolecules outside the cell wall. Bound or soluble EPSs contain not only high-molecular-weight polymeric compound exudates from microorganisms, but also products of cellular lysis and hydrolysis of macromolecules [3]. Many bacteria and fungi often secrete polysaccharides as an evolutionary adaptation to help them adhere to surfaces and to prevent them from drying out [4]. Ascomycota and Basidyomycota fungal EPSs play different biological functions, for example in the protection against environmental stress factors and in interactions with other organisms. Ascomycota and Basidyomycota fungi are used for biotechnological derivation of EPSs in laboratory conditions using similar techniques, culture conditions, sources of $\mathrm{C}, \mathrm{N}$ and other elements, culture periods, and mostly acidic $\mathrm{pH}$ of the medium [5]. Fungal strains belonging to both these groups are an important component, characterized by the highest biomass, of the microbiome of various environments [6]. Ascomycota and Basidiomycota fungi exhibit a very high variation of the weight of synthesized EPSs and their biochemical and biological properties were varied $[7,8]$. Many bioactive properties of Ascomycota and Basidiomycota EPSs such as antioxidative, antimicrobial, immunomodulatory, antitumor, hypolipidemic, hypoglycemic, and hepatoprotective activity can find medical applications. The activities of fungal EPSs in such processes as mineral sol-

*Corresponding author: Shimaa S Hussien, Assistant Professor of Microbiology, Ore Processing Department, Nuclear Materials Authority, P.O. Box 530 El-Maadi, Cairo, Egypt

Accepted: July 11, 2019

Published online: July 13, 2019

Citation: Hussien SS (2019) Biosynthesis, Extraction and Characterization of Extracellular Polymeric Substances (EPSs) from Aspergillus clavatus. Adv Environ Stud 3(1):216-228 
ubilization, heavy metal sorption and hydrocarbon removal as well as eliciting plant resistance created a possibility of potential environmental and agricultural applications of these EPSs in biofertilization, soil/water bioremediation, and plant bioprotection. The bioactive properties of EPSs are known to depend on many factors, including the structure, monosaccharide components, molecular mass, conformation, configuration of glycosidic bonds, and extraction and isolation methods [9]. Fungal EPSs are derived through ethanol precipitation with different proportions of the culture/water suspension and alcohol [10]. The directions of research on EPSs are mainly focused on identification of factors responsible for their synthesis/release, optimization of production (connected with the cost and productivity).

\section{Materials and Methods}

\section{Isolation of fungal strains}

Six isolates of fungi namely Penicillium purpurogenum, $\mathrm{Fu}$ sarium solani, Aspergillus niger, Aspergillus clavatus, Cladosporium herbarum and Epicoccum nigrum were isolated from El-Sella ore material by serial dilution method. Cultures were maintained on Cezapek's agar slants. Slants were inoculated and incubated at $30^{\circ} \mathrm{C}$ for 7 days, and stored at $4{ }^{\circ} \mathrm{C}$.

\section{Selection of most EPSs producer fungal strain by shake flask culture}

Shake flask cultures were carried out in $250 \mathrm{~mL}$ Erlenmeyer flasks containing $50 \mathrm{~mL}$ of modified Czapek's broth medium. The media consisting of the following components (in $\mathrm{g} / \mathrm{L}$ ): Sucrose, 30; $\mathrm{NaNO}_{3}, 3.0 ; \mathrm{KCl} 0.5 ; \mathrm{KH}_{2} \mathrm{PO}_{4}, 0.5 ; \mathrm{MgSO}_{4} .7$ $\mathrm{H}_{2} \mathrm{O}$ 0.5. and Yeast extract, 10. Media were sterilized at 121 ${ }^{\circ} \mathrm{C}$ for $20 \mathrm{~min}$. The $\mathrm{pH}$ was adjusted to 6.5. The flasks were incubated on a rotary shaker at $28^{\circ} \mathrm{C}$ and $150 \mathrm{rpm}$ for 2 weeks. Then, flasks were estimated for EPSs and biomass mycelial dry weights.

\section{Estimation of mycelia growth and EPSs}

Mycelial growth of $A$. clavatus was expressed as dry cell weight (DCW). The mycelia were harvested at the end of incubation periods and washed with sterile water then filtered through pre- weighed Whatman No.1 filter paper followed by drying at $60{ }^{\circ} \mathrm{C}$ for approximately 2 days in an oven to a constant weight, after which DCW were measured.

For total EPSs preparation, the culture broth without mycelia was added with $95 \%$ ethanol by two volume times to precipitate total EPSs at $4{ }^{\circ} \mathrm{C}$ overnight. After isolation of total EPSs by centrifugation at 7,200 g or 15 minutes, EPSs was resuspended with $95 \%$ ethanol and centrifuged again. The total EPSs was dried at $60^{\circ} \mathrm{C}$ and the total sugars were determined as glucose equivalents using the phenol-sulphuric acid according to Dubois, et al. [11]. $0.1 \mathrm{~g}$ of total EPSs was diluted into $1 \mathrm{~mL}$ distilled water in test tube. Then, $1 \mathrm{~mL}$ of $5 \%(\mathrm{v} / \mathrm{v})$ phenol solution and $5 \mathrm{~mL}$ of concentrated sulphuric acid were added to each tube. The mixtures were allowed to stand at room temperature for $10 \mathrm{~min}$. The prepared aliquots were read using spectrophotometer (Metertech Ino model Sp5001, UV-Visible spectrophotometer) at $490 \mathrm{~nm}$ absorbance and reducing sugars by the di-nitro salicylic acid method of Miller [12] with D-glucose as the standard. Protein was measured by the method of Lowry, et al. [13] using bovine serum albumin as standard. Elemental composition of the EPSs (content of total carbon, total nitrogen and total hydrogen) was determined using an elemental analyser Fisons Carlo Ebra $\mathrm{E}$ 1108 (France).

\section{Preparation of inoculum and cultivation of most EPSs producer fungal strain}

The mycelia of $A$. clavatus were cultured on malt extract agar medium plates containing $(\mathrm{g} / \mathrm{L})$ : malt extract 20 , dextrose 20, peptone 6 and agar 15 , at $25^{\circ} \mathrm{C}$ for 10 days and $\mathrm{pH}$ was 6 . For preparation of seed inoculums, an $6-\mathrm{cm}^{2}$ mycelium from dish culture was inoculated to an Erlenmeyer flask (250 $\mathrm{mL}$ ) containing $100 \mathrm{~mL}$ malt extract broth and incubated at 25 ${ }^{\circ} \mathrm{C}$ on a rotary shaker (150 rpm) for 8 days.

\section{Physiological factors affecting on EPSs produc- tion by $A$. clavatus}

The optimum medium composition for enhancing exopolysaccharides production was determined by studying the effect of the different media type (Potato dextrose, Czapek's dox, modified Czapek's dox and malt extract). Malt extract medium will be replaced with equimolecular weight concentrations of the following different carbon and nitrogen sources (sodium nitrate, yeast extract, peptone, urea casein as nitrogen sucrose and glucose, sucrose, starch, fructose and maltose as carbon sources), Moreover, the different $\mathrm{pH}$ $(4,5,6,7$ and 8$)$, culture type (static, shaking at $150 \mathrm{rpm}$ and shaking at $180 \mathrm{rpm})$, incubation period (5, 7, 9 and 12 days), temperatures $\left(20,25,30\right.$ and $\left.35^{\circ} \mathrm{C}\right)$ and inoculums size $1(\mathrm{~cm})$ as disc number (one, two, three and four) for EPSs production by $A$. clavatus were studied by using a conical flask containing $100 \mathrm{~mL}$ of liquid medium.

\section{Characterization of extracted exopolysaccharides (EPSs)}

Fourier-transform-infrared spectroscopy (FT-IR): FT-IR was used to investigate the vibrations of molecules and polar bonds between the different atoms. Structures of polysaccharides, such as monosaccharides types, glucosidic bonds and functional groups can be analyzed using FT-IR spectroscopy. The sample was pressed into $\mathrm{KBr}$ discs. The apparatus used (Model JASCO 4100 FTIR spectrophotometer, Japan) which presented in the Micro Analytical Center, Cairo University, Egypt.

High-performance liquid chromatography (HPLC): HPLC analysis was performed by the HPLC system (Perkin-Elmer, Waltham, MA, USA) with a Perkin-Elmer Brownlee Choice ODS column ( $150 \mathrm{~mm} \times 4.6 \mathrm{~mm}$ i.d.) and UV spectrophotometer detector LC 290. This apparatus was presented in the Micro Analytical Center, Cairo University, Egypt.

Nuclear magnetic resonance (NMR): Proton nuclear magnetic resonance $\left({ }^{1} \mathrm{H}-\mathrm{NMR}\right)$ and proton decoupled ${ }^{13} \mathrm{C}$ nuclear magnetic resonance $\left({ }^{13} \mathrm{C}-\mathrm{NMR}\right)$ were taken using dimethyl sulphoxide (DMSO) solvent. The exopolysaccaride sample 
was dissolved in $0.75 \mathrm{~mL}$ DMSO and injected through a $5-\mathrm{mm}$ OD NMR tube to record the nuclear magnetic resonance $\left({ }^{1} \mathrm{H}\right)$ (NMR) and $\left({ }^{13} \mathrm{C}\right)(\mathrm{NMR})$ at $70 \mathrm{eV}$ and also at room temperature. The ${ }^{1} \mathrm{H}-\mathrm{NMR}$ and ${ }^{13} \mathrm{C}-\mathrm{NMR}$ spectra were recorded on a Shimadzu GCMS-Qp-1000EX mass spectrometer $300 \mathrm{MHZ}$ which presented in the Faculty of Science, Cairo University, Egypt.

Mass spectroscopy: Mass spectra were obtained using a Shimadzu Qp2010-plus mass spectrometer equipped with an electrostatic and magnetic analyzer (EB part) using quadrupole ion trap (QIT) geometry and an electrospray ionization (ESI II) ion source (Japan); the spray voltage was 70 e.V and the capillary temperature $220^{\circ} \mathrm{C}$. This apparatus was presented in the Regional Center for Mycology and Biotechnology, Azhar University, Cairo, Egypt.

Thermogravimetric analysis (TGA) of EPSs extracted from $A$. clavatus: Thermal behavior of natural polymer sample was examined by Thermogravimetric Analysis Q500 (TA Instruments). The test was performed in platinum pan, at a temperature from ambient to $800{ }^{\circ} \mathrm{C}$, at heating rate of $10{ }^{\circ} \mathrm{C} / \mathrm{min}$ under nitrogen purge flow $50 \mathrm{~mL} / \mathrm{min}$. This apparatus was presented in Science and Technology Center of Excellence, Cairo, Egypt.

\section{Results and Discussion}

\section{Selection of high production exopolysaccarides (EPSs) fungal strain}

The purpose of this experiment was to study the best fungal strain which produce high level of EPSs. Six different fungal stains were isolated from El-Sella ore material which namely accordingly to $[14,15]$, Penicillium purpurogenum,
Fusarium solani, Aspergillus niger, Aspergillus clavatus, Cladosporium herbarum and Epicoccum nigrum. They were sub-cultured on potato dextrose medium, and then the isolated colonies were grown on potato dextrose broth at 25 ${ }^{\circ} \mathrm{C}$ and incubated for 8-10 days. The availability and stability for extracellular polysaccharides production were tested. It was found that fungus $A$. clavatus is the most promising one for EPSs production and mycelial growth.

The results in Figure 1 appeared that $A$. clavatus was the best strain for the production of EPSs $(60.4 \mathrm{mg} / 50 \mathrm{~mL})$. Also, Di-Hus, et al. [16] revealed that Ganoderma formosanum produce about $830.2 \mathrm{mg} / \mathrm{L}$ of EPSs under the optimum conditions for maximum production.

\section{Optimization of the fermentation conditions for maximum production of EPSs by $A$. clavatus}

Eight factors (Culture medium type, nitrogen sources, carbon sources, $\mathrm{pH}$ values, culture types, incubation periods, temperature and inoculum size) were examined independently on the EPSs production A. clavatus.

Effect of different culture medium type on EPSs production by $A$. clavatus: Potato dextrose, Czapek's dox, modified Czapek's dox and malt extract media were used to investigate the EPSs production by $A$. clavatus and initial $\mathrm{pH}$ was 6 at constant incubation temperature of $25^{\circ} \mathrm{C}$ (Figure 2). The maximum EPSs production was achieved in malt extract medium after incubation of 8-10 days in shaking incubator which produced $1.8 \mathrm{~g} / 100 \mathrm{~mL}$ of mycelial dry weight and $75 \mathrm{mg} / 100$ $\mathrm{mL}$ EPSs. On the other hand Peiqin, et al., [17], who reported that glucose peptone media with different concentration increased EPSs production of Berkleasmium sp.

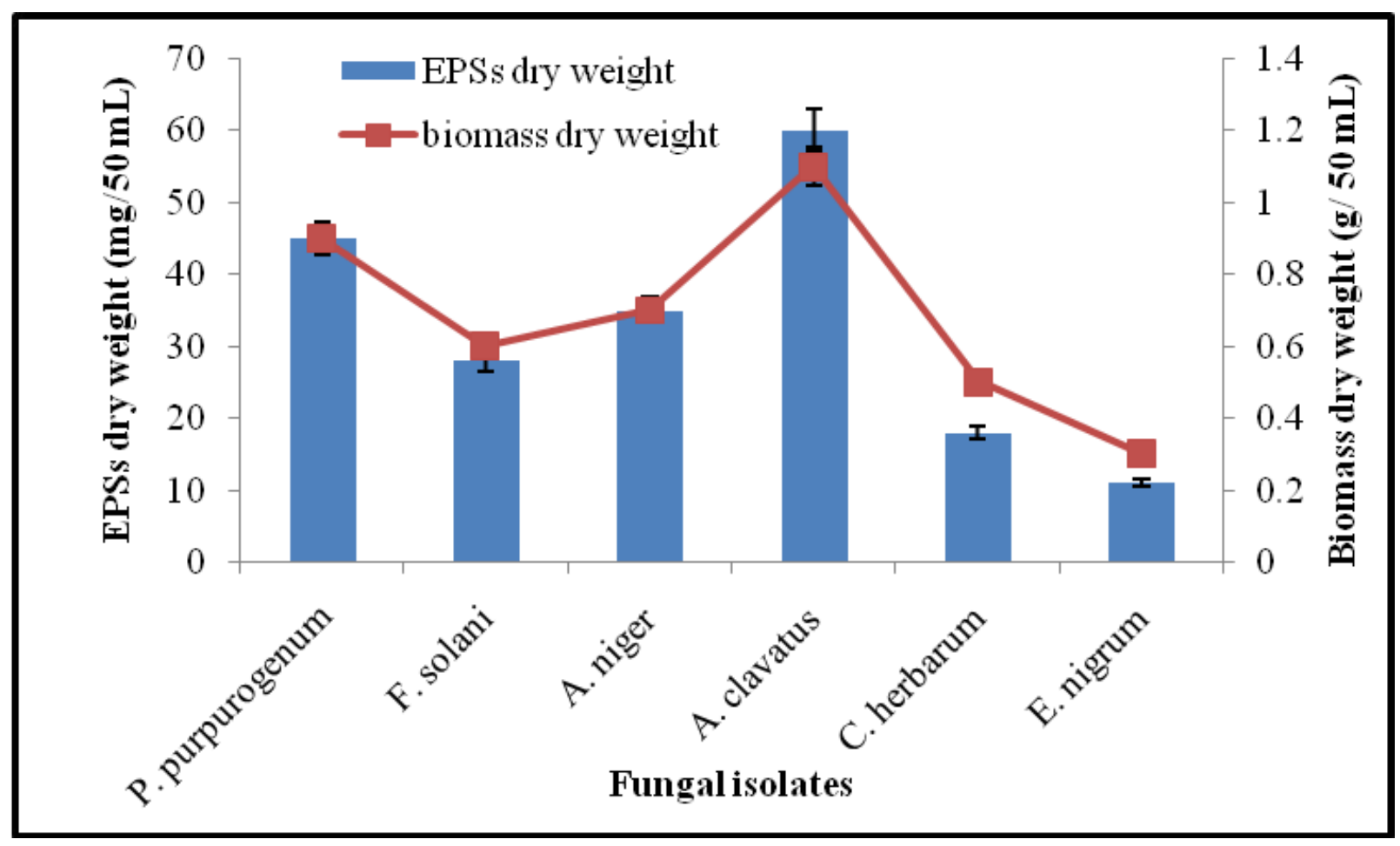

Figure 1: Production of EPSs by different fungal strains. 


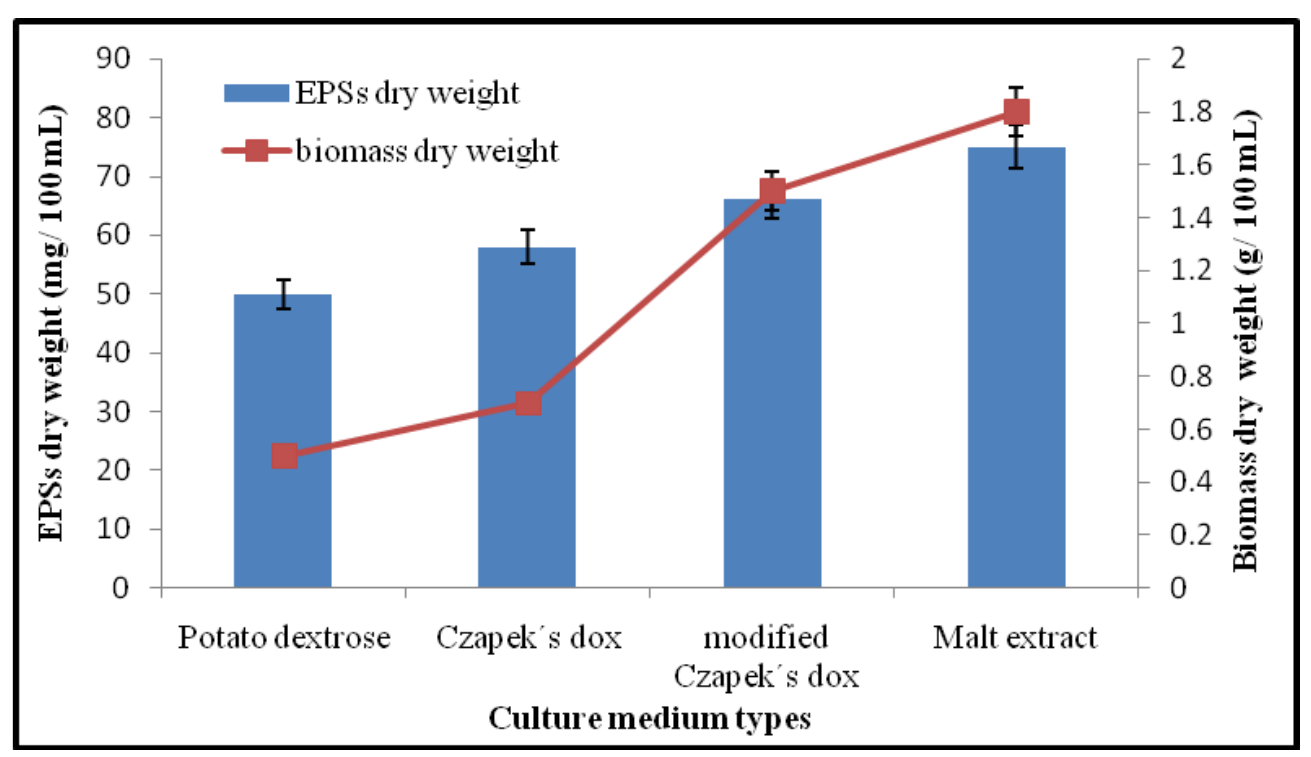

Figure 2: Effect of different culture medium type on the production of EPSs by A. clavatus.

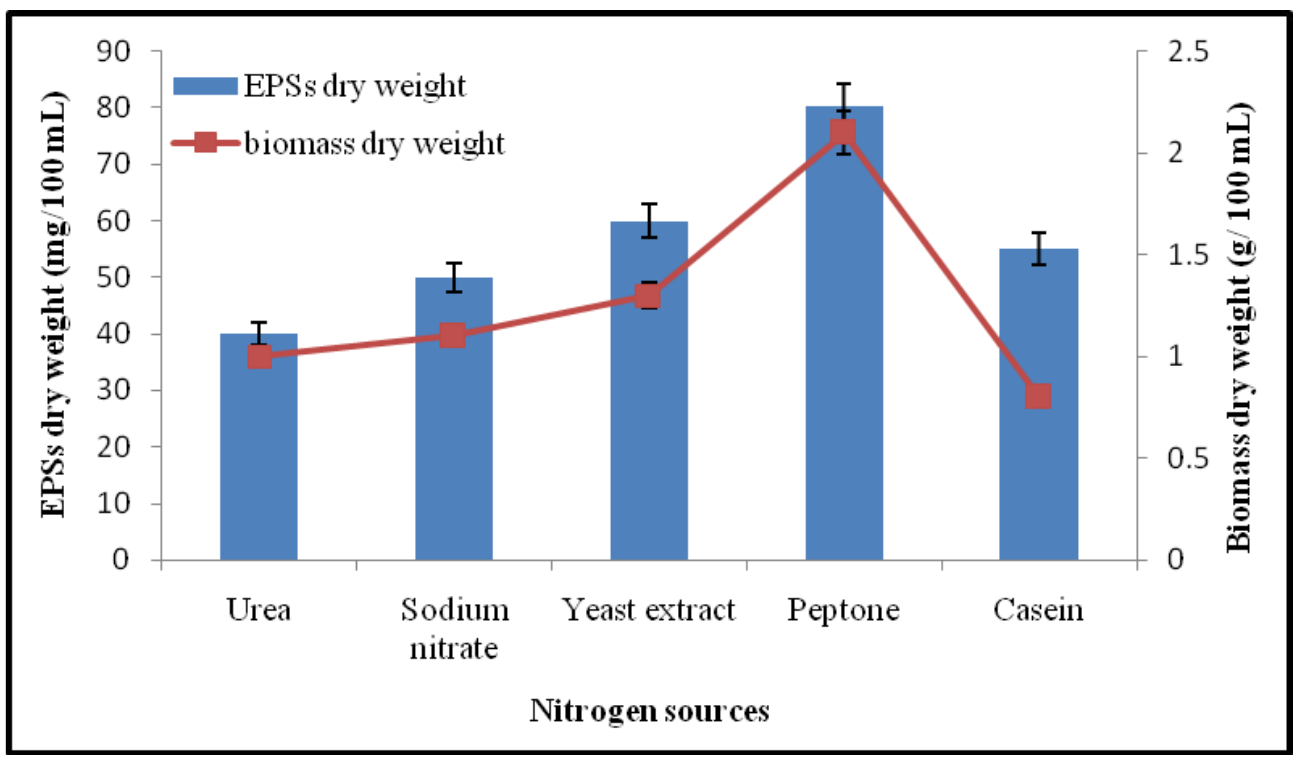

Figure 3: Effect of different nitrogen source on the production of EPSs by A. clavatus.

Effect of different nitrogen sources on EPSs production by $\boldsymbol{A}$. clavatus: Different nitrogen sources have performed effect on EPSs and biomass production. As illustrated in Figure 3 , it is evident that, EPSs concentration using peptone as nitrogen source was $80.3 \mathrm{mg} / 100 \mathrm{~mL}$ and fungal dry weight was $2.1 \mathrm{~g} / 100 \mathrm{~mL}$. The same conclusions were detected by [18] has studied that, the highest level of EPSs was obtained when peptone was used as a sole nitrogen source by Penicillium commune KP942881.1.

Effect of different carbon sources on EPSs production by A. clavatus: Carbohydrates are a major component of the cytoskeleton and an important nutritional requirement for the growth and development of higher fungi [19]. The effects of carbon sources on the production of EPSs were studied in the fermentation medium containing various carbon sources. The results in Figure 4 showed that glucose is the best carbon source for ESPs production using A. clavatus giving $81 \mathrm{mg} / 100$ $\mathrm{mL}$ and fungal dry weight was $2.15 \mathrm{~g} / 100 \mathrm{~mL}$ followed by sucrose which gave $65 \mathrm{mg} / 100 \mathrm{~mL}$. It was reported that glucose was the most suitable carbon source for EPSs and mycelium growth production in Alternaria alternata [20].

Effect of different $\mathrm{pH}$ value on EPSs production by $\boldsymbol{A}$. clavatus: The $\mathrm{pH}$ is an important parameter for the efficient production of EPSs. In fact, the $\mathrm{pH}$ in fermentation culture control and monitoring can extensively influence yield, cell morphology, chemical composition, and molecular weight of EPSs produced [21]. The study done on the submerged fermentation of $A$. clavatus has shown that the $\mathrm{pH}$ for the EPSs synthesis is lower than for the cell growth. The results in Figure 5 appeared that $\mathrm{pH} 5$ is the best one for ESPs production which giving 83.5. $\mathrm{mg} / 100 \mathrm{~mL}$ and Mycelial dry weight was $1.9 \mathrm{~g} / 100 \mathrm{~mL}$ at $\mathrm{pH} 7$. In contrast to that the curdlan as EPSs 


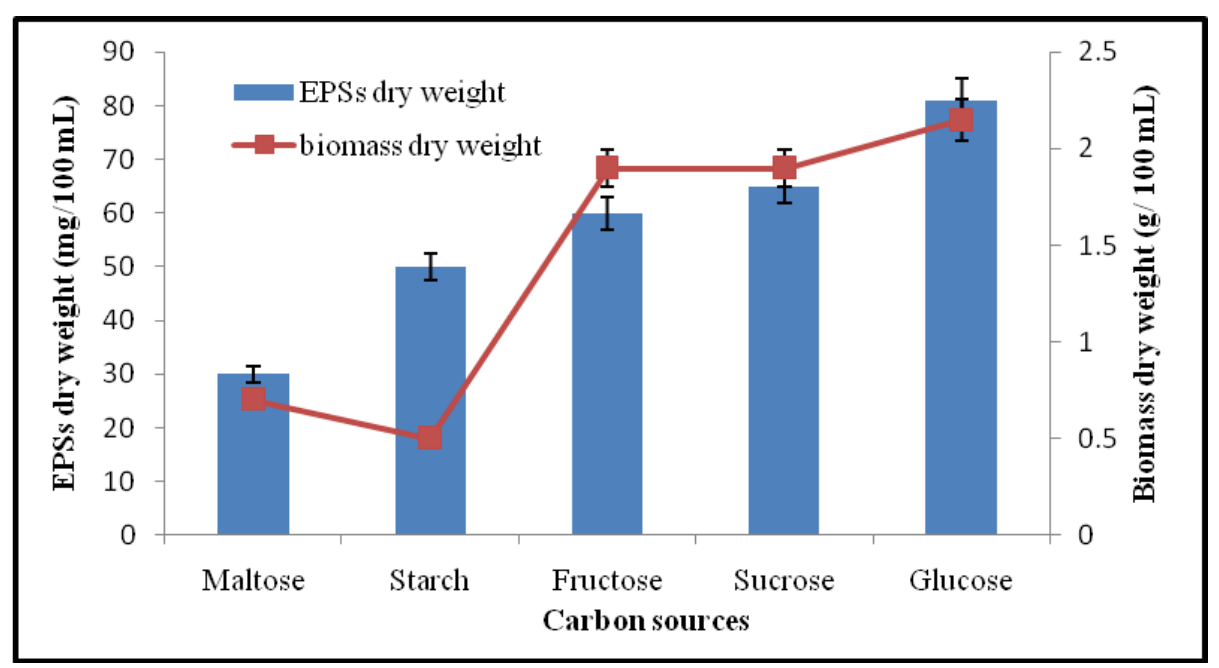

Figure 4: Effect of different carbon source on the production of EPSs by A. clavatus.

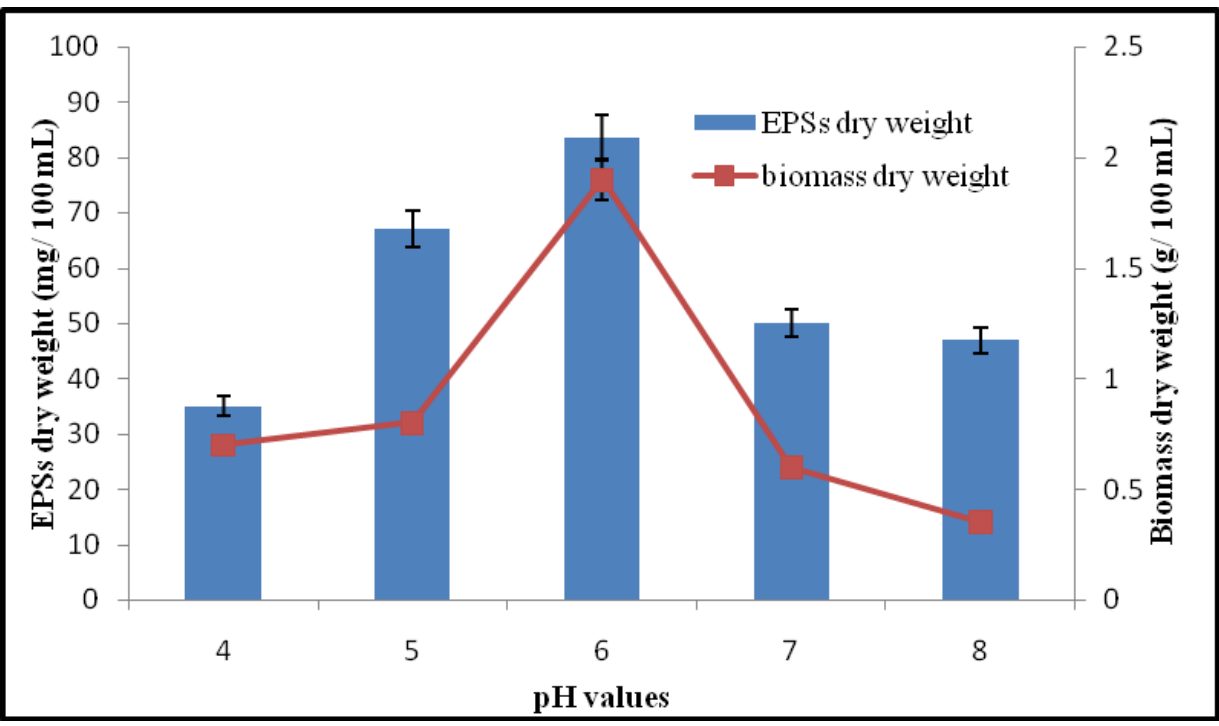

Figure 5: Effect of different $\mathrm{pH}$ values on the production of EPSs by A. clavatus.

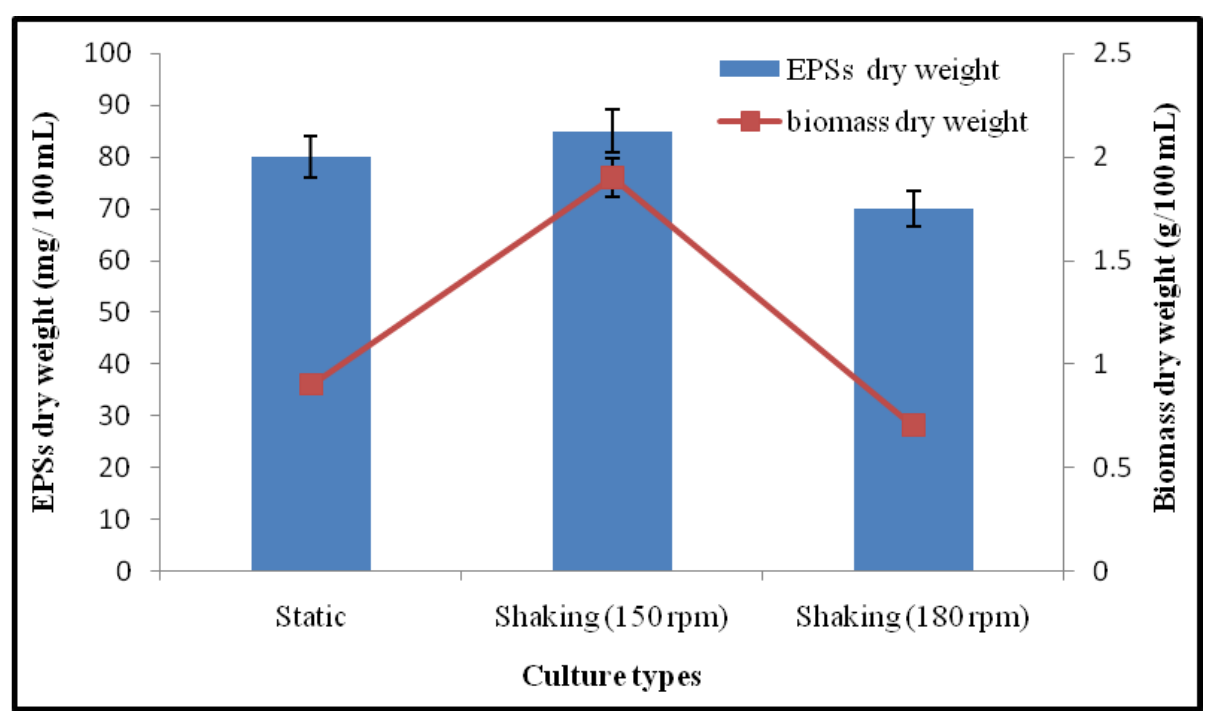

Figure 6: Effect of different culture type on the production of EPSs by A. clavatus. 
of Alcaligenes faecalis var myxogenes, the cell growth rate is optimal at $\mathrm{pH} 7.0$, whereas the EPSs production is optimal at pH 5.5 [22].

Effect of different culture type on EPSs production by $A$. clavatus: Generally, the aeration and agitation are beneficial to the growth and performance (polysaccharide productivity) of the fungal cells by improving the mixing and the heat and mass transfers [23]. From the data presented in Figure 6 , shaking condition (150 rpm) was the suitable condition for high mycelial growth production and EPSs of $A$. clavatus. The EPSs concentration in shaking condition was $85 \mathrm{mg} / 100 \mathrm{~mL}$ and mycelial dry weight was $1.9 \mathrm{~g} / 100 \mathrm{~mL}$. so, shaking (150 $\mathrm{rpm}$ ) condition was selected as the most suitable condition for EPSs production in the subsequent experiments. These results agreed with $\mathrm{Kim}$, et al. [24] have investigated the influence of the aeration rate and agitation intensity on the production of mycelial biomass and EPSs from the enthomopathogenis fungus Paecilomyces sinclairii.

Effect of different incubation period on EPSs production by $\boldsymbol{A}$. clavatus: The incubation for 9 days was the most promising for EPSs production and mycelial growth of $A$. clavatus. It was clear that there was a gradual increase in the fungal growth from 5 to 9 days (Figure 7). So, incubation for 9 days was applied for the other experiments. The EPSs concentration was $87 \mathrm{mg} / 100 \mathrm{~mL}$ under shaking (150 rpm) condition at $30{ }^{\circ} \mathrm{C}$. Mycelial dry weight was $1.9 \mathrm{~g} / 100 \mathrm{~mL}$. Chen, et al. [25] reported that 10 days was suitable for EPSs production by Penicillium commune.

Effect of different temperature $\left({ }^{\circ} \mathrm{C}\right)$ on EPSs production by $A$. clavatus: The data in Figure 8 , it is evident that temperature $30^{\circ} \mathrm{C}$ was the optimum for EPSs production and mycelial growth of $A$. clavatus. The EPSs concentration was $87.8 \mathrm{mg} / 100 \mathrm{~mL}$ under shaking condition. Mycelial dry weight was $2.2 \mathrm{~g} / 100 \mathrm{~mL}$. Nehad and Elshamy [20] proved that $30^{\circ} \mathrm{C}$ was suitable for EPSs production by Alternaria alternate.

Effect of different inoculum size (disc number) on the production of EPSs by $A$. clavatus: It was observed that three disc sized $1 \mathrm{~cm}$ in diameter from $P$. commune gave high EPS dry weight and high mycelial dry weight. Cultivation of three fungal discs with diameter $1 \mathrm{~cm}$ from tested organism on malt

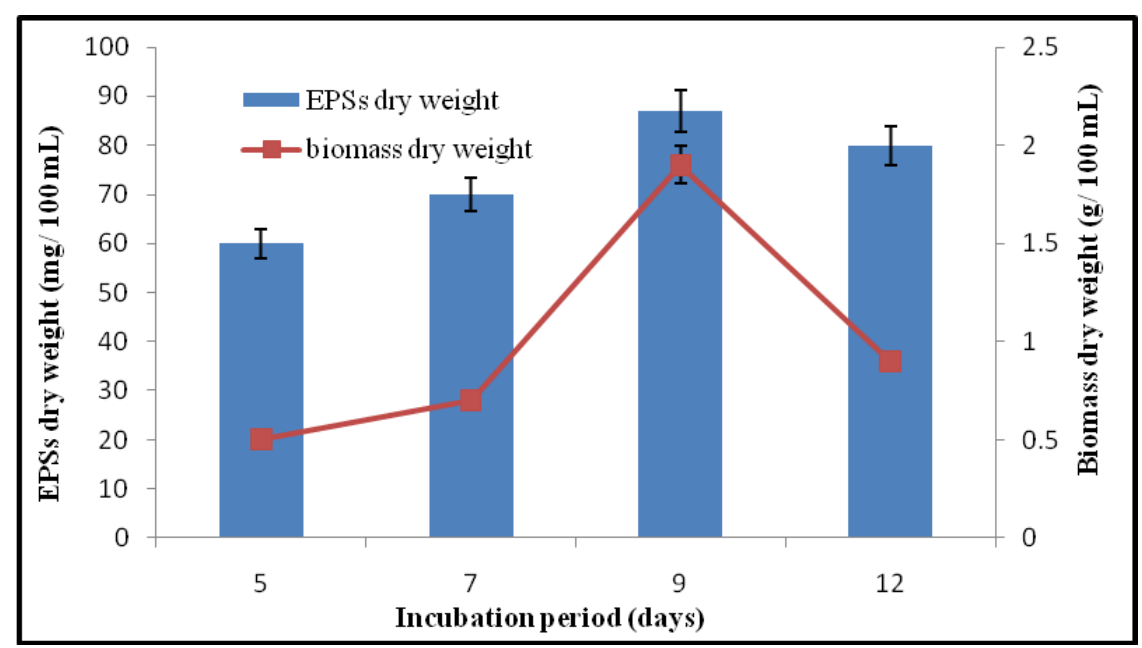

Figure 7: Effect of different incubation period (days) on the production of EPSs by A. clavatus.

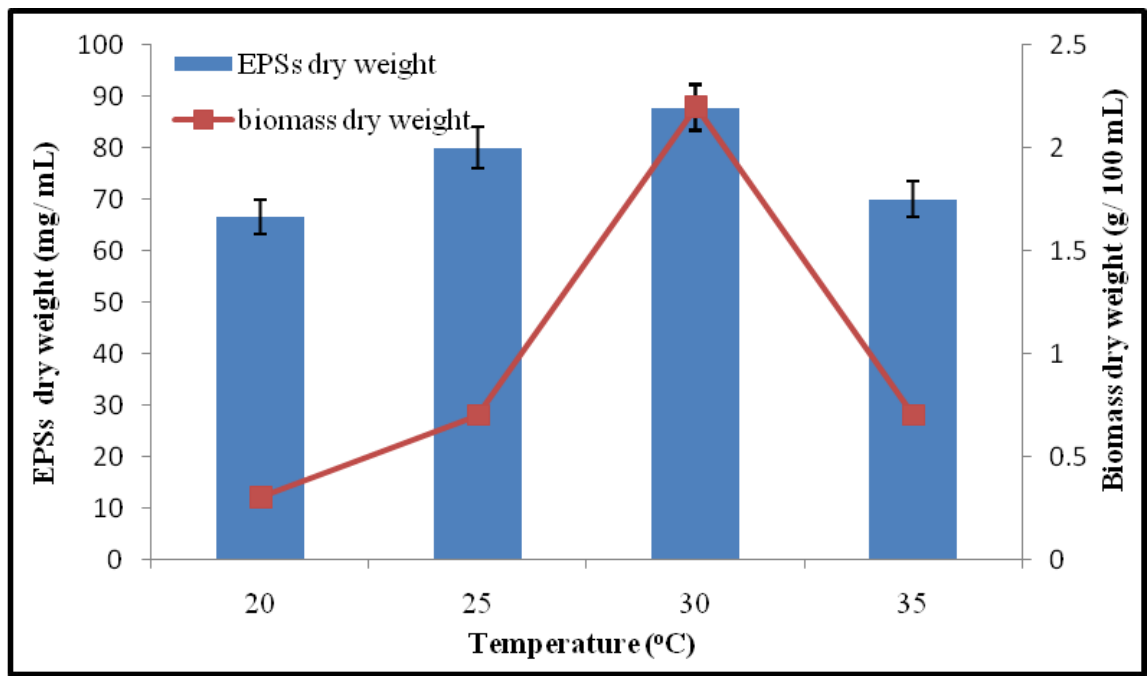

Figure 8: Effect of different temperature $\left({ }^{\circ} \mathrm{C}\right)$ on the production of EPSs by A. clavatus. 


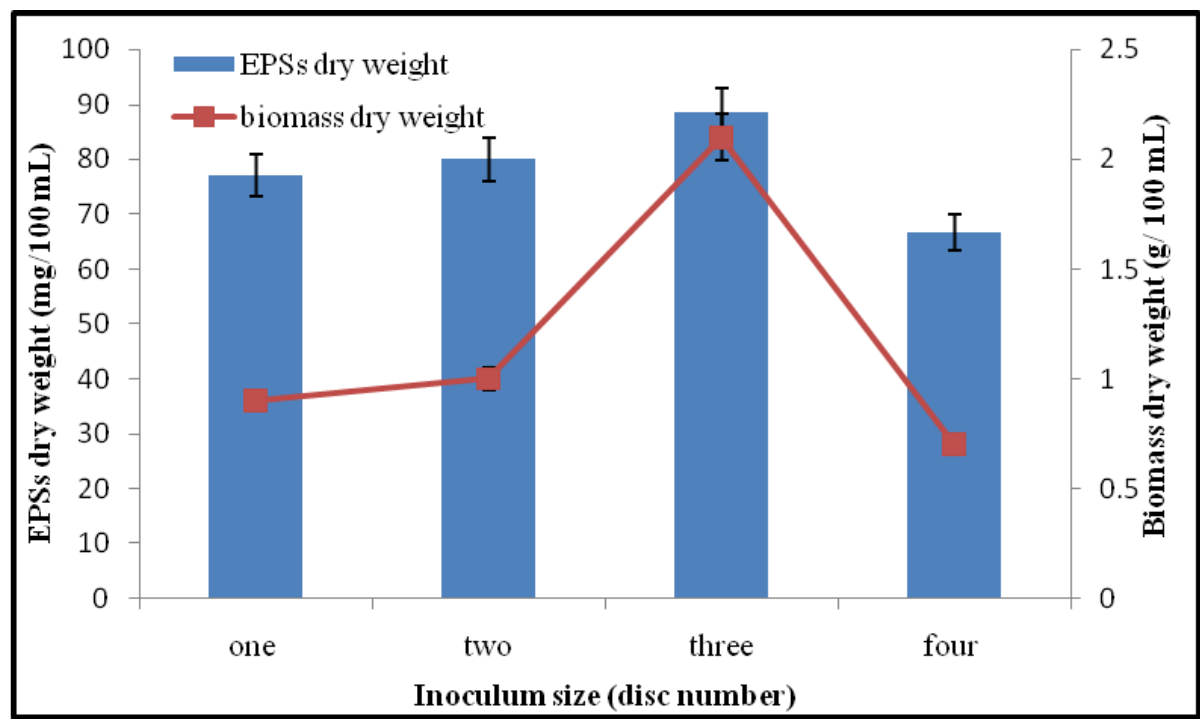

Figure 9: Effect of different inoculums size (disc number) on the production of EPSs by A. clavatus.

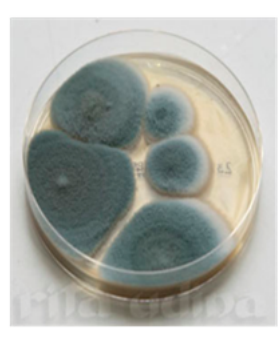

A. clavatus

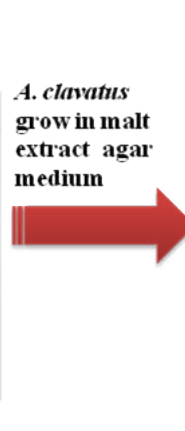

A. clavatus nedium

* The obtained EPSs dried at $60^{\circ} \mathrm{C}$ will be characterized by several techniques for identification as : FT-IR, HPLC, NMR and Mass spectroscopy.
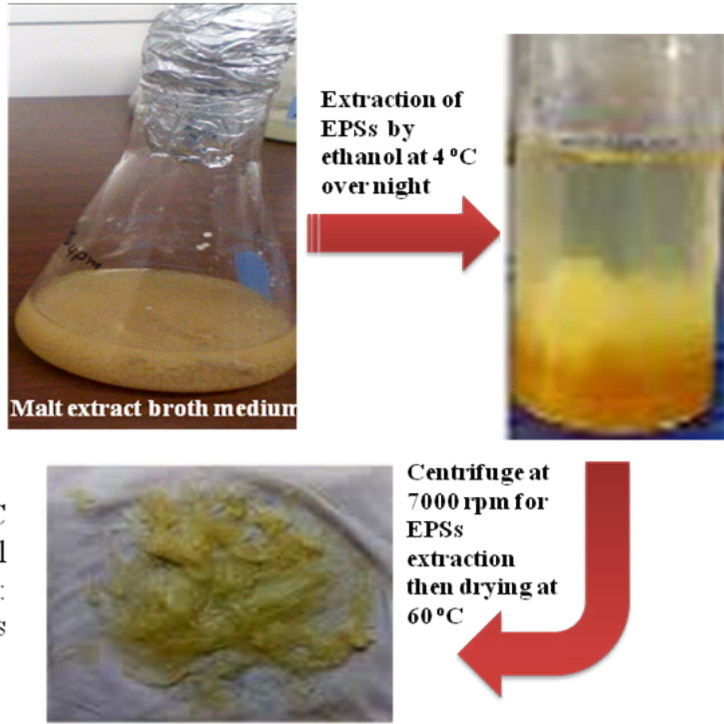

Figure 10: Simplified scheme illustrating the extraction of EPSs from A. clavatus.

extract media at shaking (150 rpm) condition for 9 days gave high quantity of EPSs ( $88.5 \mathrm{mg} / 100 \mathrm{~mL}$ ) and dry mycelial (2 $\mathrm{g} / 100 \mathrm{~mL}$ ) (Figure 9). Yun, et al. [26] found that inoculum size ( $5 \mathrm{~mm}$ ) of Cordyceps militaris was the most favorable for exopolysaccharides production. Osman, et al. [27] observed that increasing the inoculum size led to a significant increase in growth and polysaccharides production.

Under these optimum conditions for EPSs production, the biosynthesis and extraction of it from $A$. clavatus were evaluated in Figure 10.

\section{Estimation of chemical and elemental composi- tions of EPSs produced by $A$. clavatus}

Total carbohydrates, reducing sugar, total protein and elemental composition of the EPSs produced by $A$. clavatus were estimated and the results are presented in Table 1. Total carbohydrates $(8.23 \mathrm{mg} / 100 \mathrm{~mL})$, reducing sugar $(1.03$ $\mathrm{mg} / 100 \mathrm{~mL})$, protein $(2.02 \mathrm{U} / \mathrm{mL})$ were recorded. In addition to, the elemental compositions carbon $(24.89 \%)$, hydrogen (5.26), nitrogen (1.95\%) and $\mathrm{C} / \mathrm{N}$ (21.76 mol/ratio) were evaluated.

There was a clear trend that EPSs have larger carbohydrates contents; in the present study, in the present study, the reducing sugar, protein and nitrogen contents in EPSs was low as compared to total carbohydrate content. Similar results were also observed by Sharmila, et al. [28] where they recorded that, very low contents of in culture filtrate of the reducing sugar $(2.82 \mathrm{~g} / 100 \mathrm{~mL})$, protein $(2.30 \mathrm{U} / \mathrm{mL})$ and nitrogen $(0.38 \mathrm{~g} / 100 \mathrm{~mL})$ compared to the total carbohydrate content (14.43 g/100 mL).

\section{Characterization of extracted EPSs}

Fourier-transform-infrared spectroscopy (FT-IR): The spectrum of the purified EPSs produced by $A$. clavatus was 
determined (Figure 11). The IR-spectra showed absorption bands and peaks characteristic of carbohydrate, carboxylate, and hydroxyl groups as well as urinate, amine and C-O-C ester linkages. The spectrum of extracted EPSs revealed that a dominant absorption that is often attributed to $\mathrm{O}-\mathrm{H}$ stretching vibration at $3848.26 \mathrm{~cm}^{-1}$ of $\mathrm{O}-\mathrm{H}$ in carboxylic acid which is accompanied with the bands at $2932.23 \mathrm{~cm}$ 1 , known to be typical carbohydrates which corresponds to $\mathrm{C}-\mathrm{H}$ asymmetric stretching vibration in carboxylic group. The band at $2342.34 \mathrm{~cm}^{-1}$ approves the bending vibration of $\mathrm{P}-\mathrm{H}$ phosphine group. An asymmetrical stretching peak observed at $1641.13 \mathrm{~cm}^{-1}$ is characteristic of $\mathrm{C}=\mathrm{C}$ medium stretching vibration in conjugated alkene. The band observed at $1418 \mathrm{~cm}^{-1}$, indicated the presence of urinate. The spectrum also displayed a minor peak at $1379.82 \mathrm{~cm}^{-1}$, indicating the presence of carboxylate in the polymer. The peak at 1238.82 $\mathrm{cm}^{-1}$ identifies the medium vibration stretching of amine $\mathrm{C}-\mathrm{N}$ in amine group. In addition, the absorption band at 1062.59 $\mathrm{cm}^{-1}$ indicated asymmetrical stretching vibration of a C-O-C ester linkage. The small absorption band at $877.45 \mathrm{~cm}^{-1}$ could be associated with glycosidic linkages between the sugar monomers. The absorption peaks around $1000-1100 \mathrm{~cm}^{-1}$ are known to be characteristic for all sugar derivatives.

Table 1: Chemical and elemental compositions of EPSs produced by A. clavatus at optimum production conditions.

\begin{tabular}{|l|l|l|l|}
\hline \multicolumn{3}{|l|}{ EPSs chemical compositions } & \multicolumn{2}{l|}{$\begin{array}{l}\text { EPSs elemental } \\
\text { compositions }\end{array}$} \\
\hline $\begin{array}{l}\text { Weight of polysaccharides } \\
\text { (mg/100 mL) }\end{array}$ & 88.5 & C (\%) & 24.89 \\
\hline $\begin{array}{l}\text { Total carbohydrates } \\
\text { (mg/100 mL) }\end{array}$ & 8.23 & H (\%) & 5.26 \\
\hline $\begin{array}{l}\text { Reducing sugar } \\
\text { (mg/100 mL) }\end{array}$ & 1.03 & $\mathbf{N ~ ( \% ) ~}$ & 1.95 \\
\hline Protein (U/mL) & 2.02 & C/N mol ratio & 21.76 \\
\hline
\end{tabular}

The IR-spectrum, in our study, is in consistent with the results reported previously [29]. Thus, the EPSs from A. clavatus contains important functional groups such as carboxyl and hydroxyl. The carboxyl groups present on the molecular chain make the chain stretched-out because of electrostatic repulsion, and the stretched molecular chains provide more effective sites for particle attachment [30]. Furthermore, carboxylate groups act as non-specific ion-exchange material which may convey chelating property [29]. In addition, presence of hydroxyl group within the polymer favored the possibility of hydrogen bonding with one or more water molecules [31]. Presence of urinate assists metal uptake and allows for adhesion of microorganisms to surfaces.

High-performance liquid chromatography (HPLC) analysis of hydrolyzed EPSs-derivatized monosaccharide: The EPSs-derivatized monosaccharide was monitored by an UV detector (Perkin-Elmer) at $245 \mathrm{~nm}$ with detector (RI) reflected indict and the flow rate was maintained at $2 \mathrm{~mL} / \mathrm{min}$. The sample was eluted with a gradient mobile phase consisting of acetonitrile (75\%) and dist. $\mathrm{H}_{2} \mathrm{O}(25 \%)$. The monosaccharide composition of EPSs was determined by the method of sugar using a HPLC analysis technique [32].

For the total hydrolysis of EPSs trifluoroacetic acid (TFA) has important advantages over sulfuric acid. The reaction time is short and there is no need for conventional neutralization, as TFA is volatile and can be removed by evaporation [33]. HPLC analysis suggested that EPSs consisted of only glucose as a monosaccharide unit (Figure 12). This obtained result agreement with that obtained by [34].

\section{Nuclear magnetic resonance (NMR)}

Proton nuclear magnetic resonance $\left({ }^{1} \mathrm{H}\right.$ NMR): The ${ }^{1} \mathrm{H}$ NMR spectrum of the EPSs produced from $A$. clavatus was illustrated in Figure 13 which showed signals of hydrogens that corresponded to the glucosyl residue. The carbonyl hydrogens of D-glucopyranose were observed as a triplet $(t)$ in signals around $\delta 3.32$ to $3.50 \mathrm{ppm}$. The doublet signals from

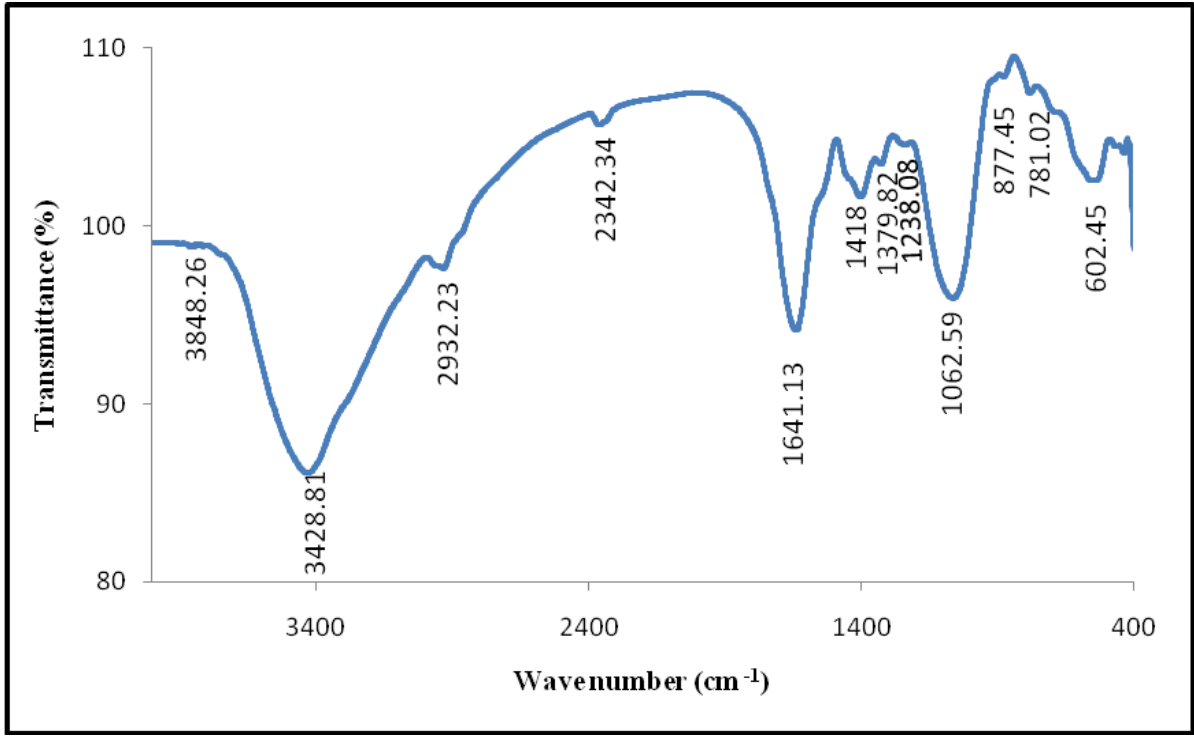

Figure 11: FT-IR spectrum of exopolysaccarides from $A$. clavatus. 


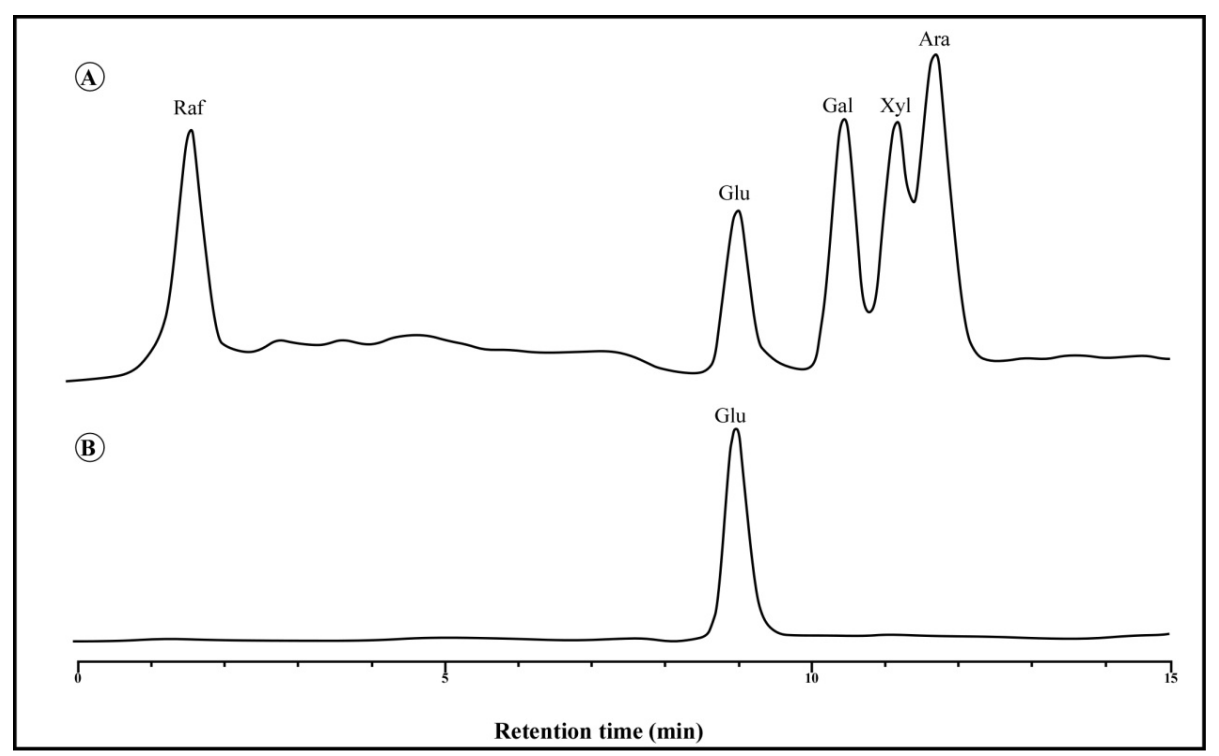

Figure 12: HPLC chromatogram of EPSs- derivatized monosaccharide. A) Standard sugars; B) Acidic hydrolysate of EPSs.

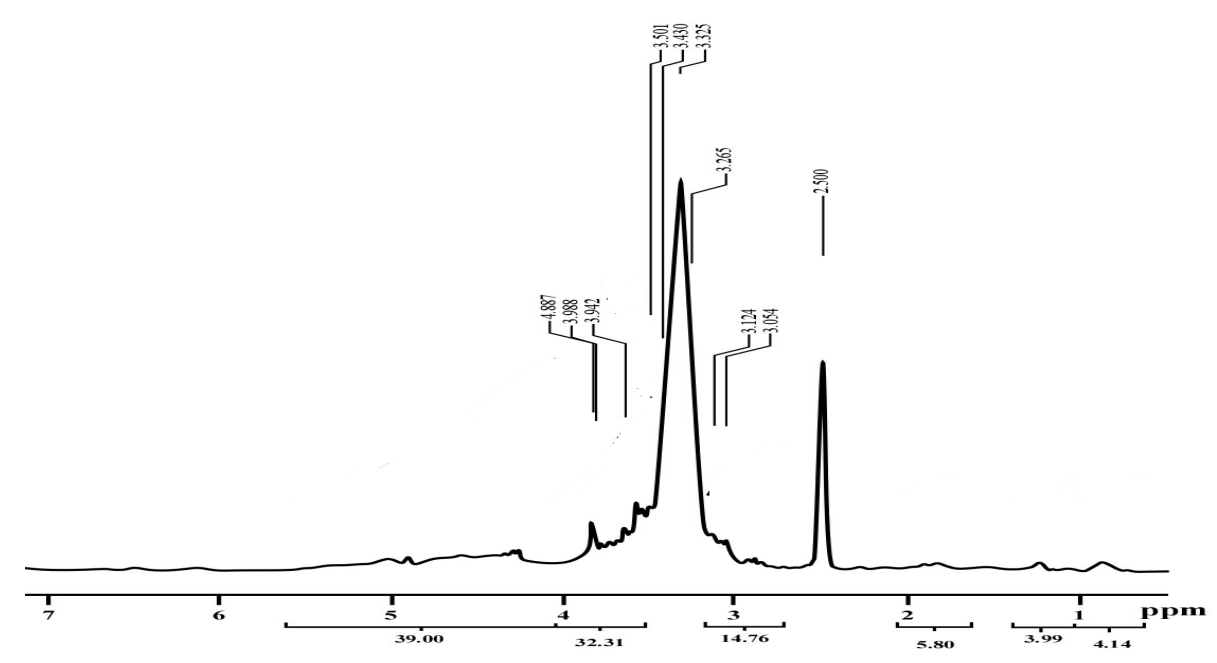

Figure 13: ${ }^{1} \mathrm{H}$ NMR spectrum of EPSs produced by A. clavatus ( $300 \mathrm{MHZ}$, in DMSO).

$\delta 3.05$ and $3.12 \mathrm{ppm}$ were observed to methane protons, respectively. Finally, a singlet was observed in $\delta 4.88 \mathrm{ppm}$ due to anomeric hydrogen $(\mathrm{H}-1)$ and it was attached with carbon atom $\mathrm{C}-1$. The remaining methane protons were observed at $3.98,3.91$ and 3.77 ppm, respectively.

Carbon nuclear magnetic resonance $\left({ }^{13} \mathrm{C} N M R\right)$ : The ${ }^{13} \mathrm{C}$ NMR spectrum of the EPSs is shown in Figure 14 The ${ }^{13} \mathrm{C}$ NMR spectrum of EPSs was compared with that of $\alpha$-D-glucans [35]. It was found that, two main peaks at $\delta$ C100.28 ppm and $\delta$ C99.48 ppm corresponded to the anomeric proton of the $\rightarrow 6-$ Glcp-1 linked residue (main chain or side chain) and $\rightarrow 4$-Glcp-1 linked residue (side chain), respectively. C-2 at $\delta 73.01 \mathrm{ppm} ; \mathrm{C}-3$ at $\delta 74.13 \mathrm{ppm} ; \mathrm{C}-4$ at $\delta 78.11 \mathrm{ppm}$; C-5 at $\delta 71.30 \mathrm{ppm} ; \mathrm{C}-6$ at $\delta 62.41 \mathrm{ppm} .{ }^{13} \mathrm{C}$ NMR resonances within the $\delta 70$ to $78 \mathrm{ppm}$ region are associated with free positions at $\mathrm{C}-2, \mathrm{C}-3$ and $\mathrm{C}-4$ residues. No additional peaks were observed in the region of $\delta 78-85 \mathrm{ppm}$, indicating that may be confirming that the glucans synthesized by $A$. clavatus is a highly linear glucans with $\alpha(1 \rightarrow 6)$ and $(1 \rightarrow 4)$ glycosidic bonds.

All data from NMR experiments $\left({ }^{1} \mathrm{H}\right.$ and $\left.{ }^{13} \mathrm{C}\right)$ for the EPSs and commercial D-glucose, as well as the published reports used to confirm the structures of the exopolysaccharides, are summarized in Table 2.

Mass spectrometry: The mass spectrum of EPSs extracted from $A$. clavatus appeared the fragmentation pattern in Figure 14 with a retention time $3.4 \mathrm{~min}$ and relative abundance $98 \%$. The presence of $85.16,103.24,149.23,331.32$ and $368.55 \mathrm{~m} / \mathrm{z}$ ions are inductive that mainly the same of fragmentation of the standard $\alpha$-D-glucopyranosyl unit. The observed ions in the mass spectrum were also compared with the documented standard of trehalose which consists of 89 , 119, 103, 179, 341 and 361 ions Jiang and Coli [36]. From the Figure 15, it was found that, the main product in the produced polysaccharides (EPSs) was consists from $\alpha$-D-glucopyranosyl unit $\left(\mathrm{C}_{12} \mathrm{H}_{22} \mathrm{O}_{11}\right)$ with molecular weight $342 \mathrm{~g} / \mathrm{moL}$. 


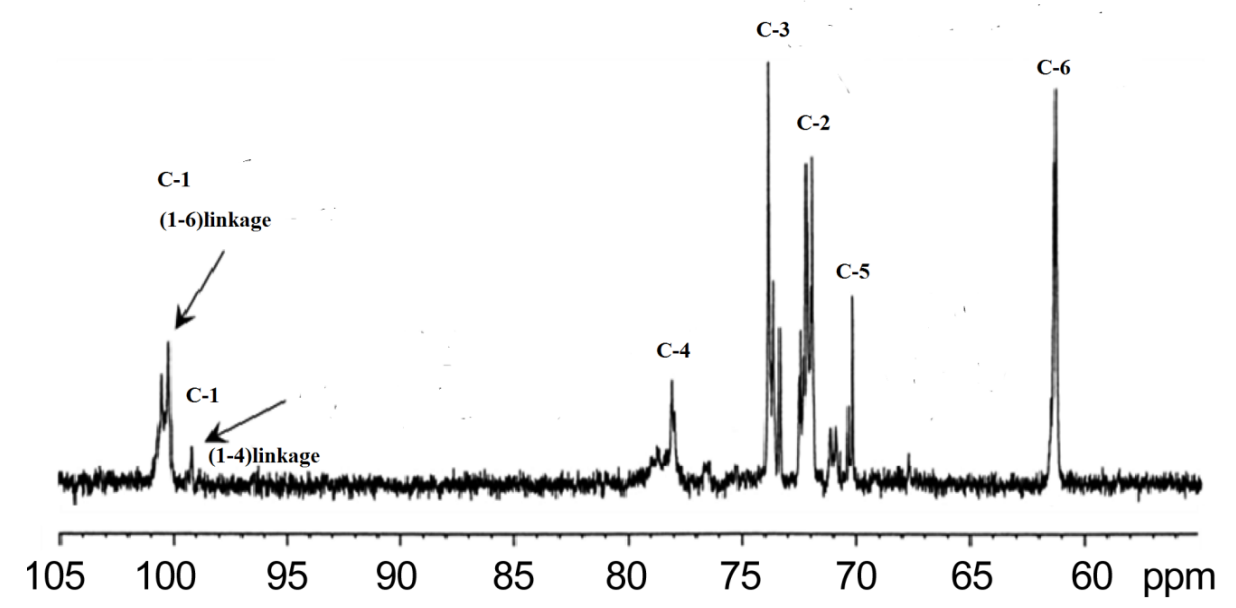

Figure 14: ${ }^{13} \mathrm{C}$ NMR spectrum of EPSs produced by A. clavatus ( $300 \mathrm{MHZ}$, in DMSO).

Table 2: ${ }^{1} \mathrm{H},{ }^{13} \mathrm{C}$ NMR data for EPSs produced by $A$. clavatus and literature data [17].

\begin{tabular}{|l|l|l|l|l|}
\hline \multirow{2}{*}{ Position } & \multicolumn{2}{l|}{ EPSs (experimental) } & \multicolumn{2}{l|}{ Literature [17] } \\
\hline & ${ }^{1} \mathbf{H} \boldsymbol{C}$ & ${ }^{13} \mathbf{C}$ & ${ }^{1} \mathbf{H} \boldsymbol{~}$ & ${ }^{13} \mathbf{C}$ \\
\hline 1 & $4.88 \mathrm{ppm}$ & $100.8(\mathrm{CH})$ & $4.99 \mathrm{ppm}$ & 100.6 \\
\hline 2 & $3.50 \mathrm{ppm}$ & $73.01(\mathrm{CH})$ & $3.58 \mathrm{ppm}$ & 74.3 \\
\hline 3 & $3.77 \mathrm{ppm}$ & $74.13(\mathrm{CH})$ & $3.74 \mathrm{ppm}$ & 76.3 \\
\hline 4 & $3.53 \mathrm{ppm}$ & $78.11(\mathrm{CH})$ & $3.53 \mathrm{ppm}$ & 73.0 \\
\hline 5 & $3.94 \mathrm{ppm}$ & $71.30(\mathrm{CH})$ & $3.92 \mathrm{ppm}$ & 72.4 \\
\hline 6 & $3.98 \mathrm{ppm}$ & $62.41\left(\mathrm{CH}_{2}\right)$ & $3.99 \mathrm{ppm}$ & 68.4 \\
\hline
\end{tabular}

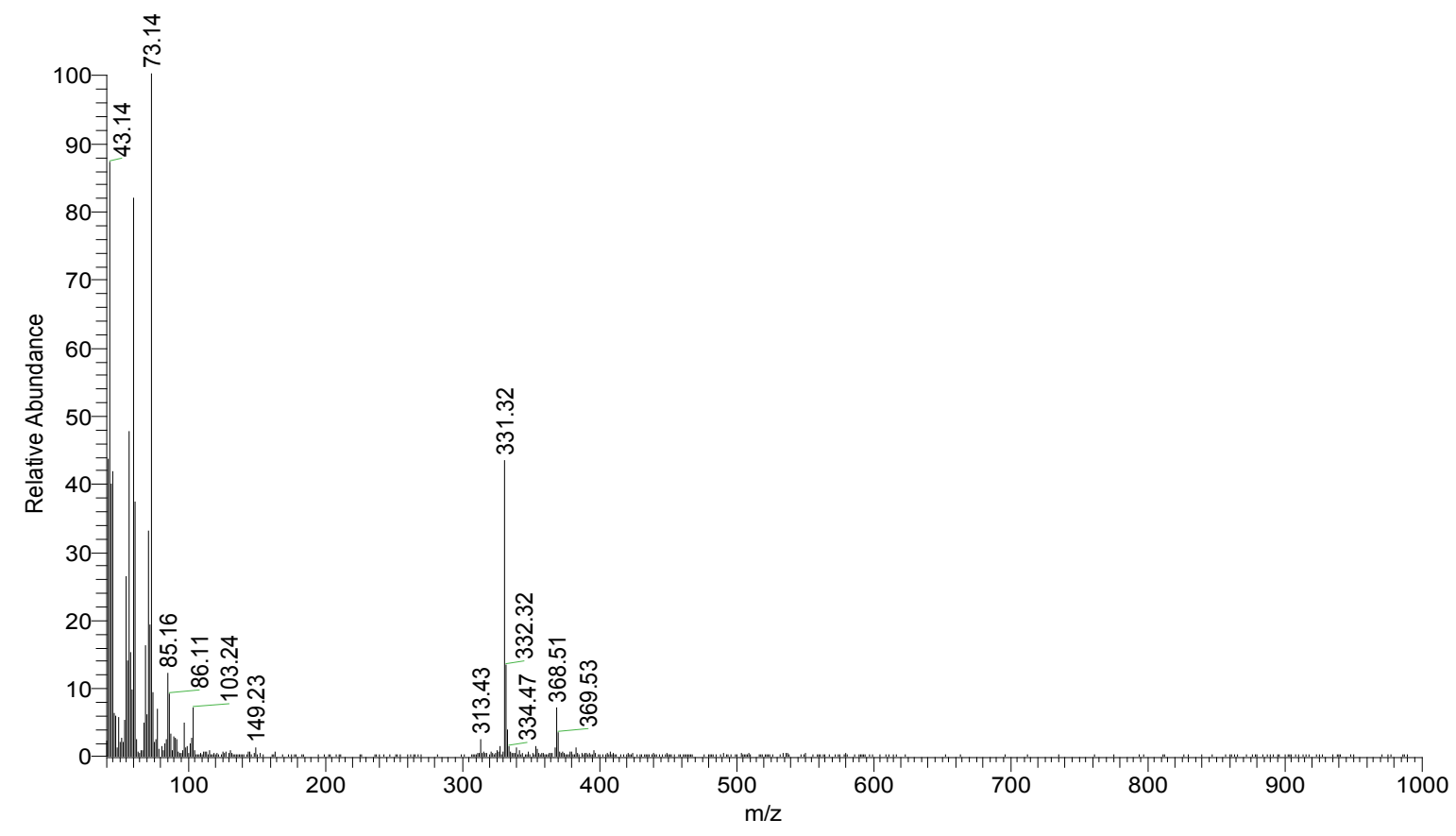

Figure 15: Mass spectrum of EPSs produced by A. clavatus.

The fragmentation pattern of the second tall peak in Figure 16 with a retention time of $3.3 \mathrm{~min}$ and relative abun- dance $95 \%$ is shown in Figure 16 . This figure gives the average and monoisotopic residue masses for the common amino 


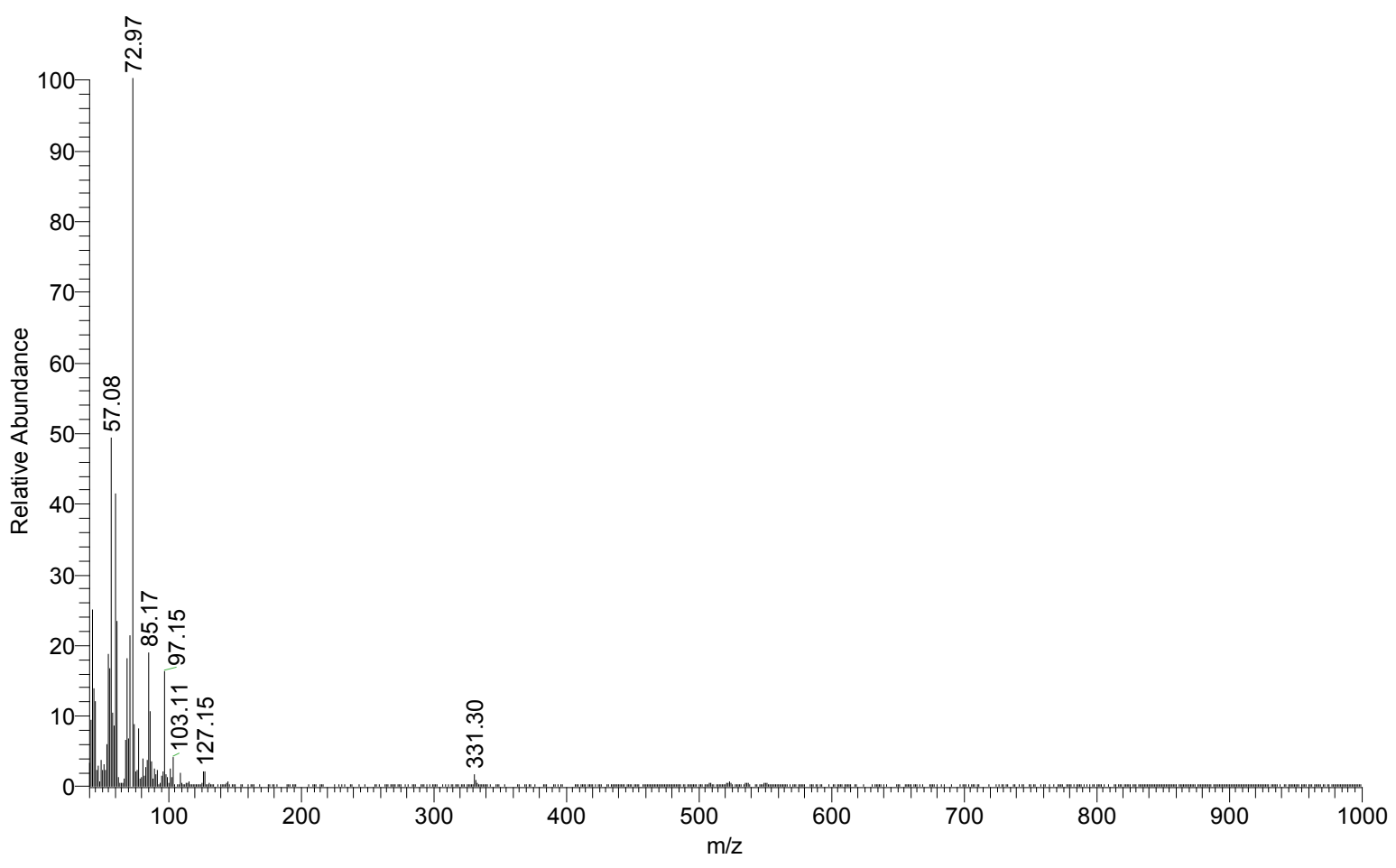

Figure 16: Mass spectrum of the second tall peak of EPSs produced by A. clavatus.

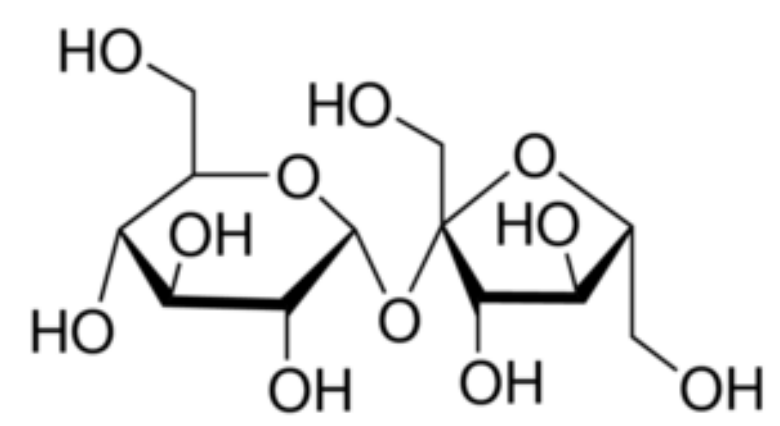

Figure 17: Chemical structure the $\alpha$-D-glucopyranosyl repeating unit of EPSs.

acids. It was observed that, 57.08, 72.97, 85.17, 97.15 and $103.11 \mathrm{~m} / \mathrm{z}$ ions were for glycine, alanine, serine, proline and cysteine. These obtained ions in the mass spectrum were also observed for the mass of an amino acid within a peptide [37].

Based on the FT-IR, HPLC, NMR and mass spectroscopy, it revealed that EPSs produced by $A$. clavatus containing composed of $\alpha$-D-glucopyranosyl units (Figure 17) and glucose was the predominant monosaccharides in polysaccharide units.

Other previous study revealed that, polysaccharide fraction could be ascertained with the help of IR-spectroscopy. Based on the TLC, FT-IR and NMR spectroscopy revealed that cell wall of Syncephalastrum sp. contain 3 linked $\beta$-D-galactopyronosyl units, and galactose as predominant monosaccharides in polysaccharide units [28].

Thermogravimetric analysis (TGA) of EPSs extracted from A. clavatus: TGA technique is important to investigate the thermal stability of natural polymer under heat from ambient up to $800^{\circ} \mathrm{C}$. TG \& DTG curves appear in Figure $18 \mathrm{lt}$ is clear that the decomposition of the polymer has occurred at three stages as listed in Table 3. The first stage drop starts early up to $200{ }^{\circ} \mathrm{C}$, it was connected with boundary water evaporation and the total moisture content was approx. $32 \mathrm{wt} \%$. The second stage start from 205 to $300{ }^{\circ} \mathrm{C}$, it was starting with dissociation of the polymer chain such as carbon dioxide, carbon monoxide. Finally, the third stage start from 300 to $800{ }^{\circ} \mathrm{C}$, it included the dissociation of the polymer chain releasing different gaseous materials such as acetic acid and crystalline water in [38]. The gaseous content was approx. $25.2 \mathrm{wt} \%$.

\section{Conclusion}

This present study focused on the production, extraction and characterization of EPSs from $A$. clavatus. Maximum production of the EPSs from $A$. clavatus was achieved under shaking condition on malt extract medium at $30{ }^{\circ} \mathrm{C}$ and initial $\mathrm{pH} 5$ for 9 days where glucose and peptone were the best carbon and nitrogen sources. The EPSs was purified by successive extraction and precipitation by $95 \%$ ethanol. FTIR spectrum analysis of EPSs indicated the presence of $\mathrm{C}=\mathrm{O}$, $\mathrm{C}-\mathrm{O}-\mathrm{C}, \mathrm{CH}_{2}$ and $\mathrm{OH}$ groups and also confirmed the presence of glycosidic linkage. HPLC chromatography showed that the EPSs consisted of one peak; glucose. ${ }^{1} \mathrm{HNMR}$ analysis of EPSs confirmed presence of the carbonyl hydrogens of D-glucopyranose $(\mathrm{H}-4)$ were observed as a triplet $(\mathrm{t})$ in $\delta 3.50 \mathrm{ppm}$. In addition to, The ${ }^{13} \mathrm{C}$ NMR spectrum of EPSs may be confirming that the glucans synthesized by $A$. clavatus is a highly linear glucans with $\alpha(1 \rightarrow 6)$ and $(1 \rightarrow 4)$ glycosidic bonds. Finally, 


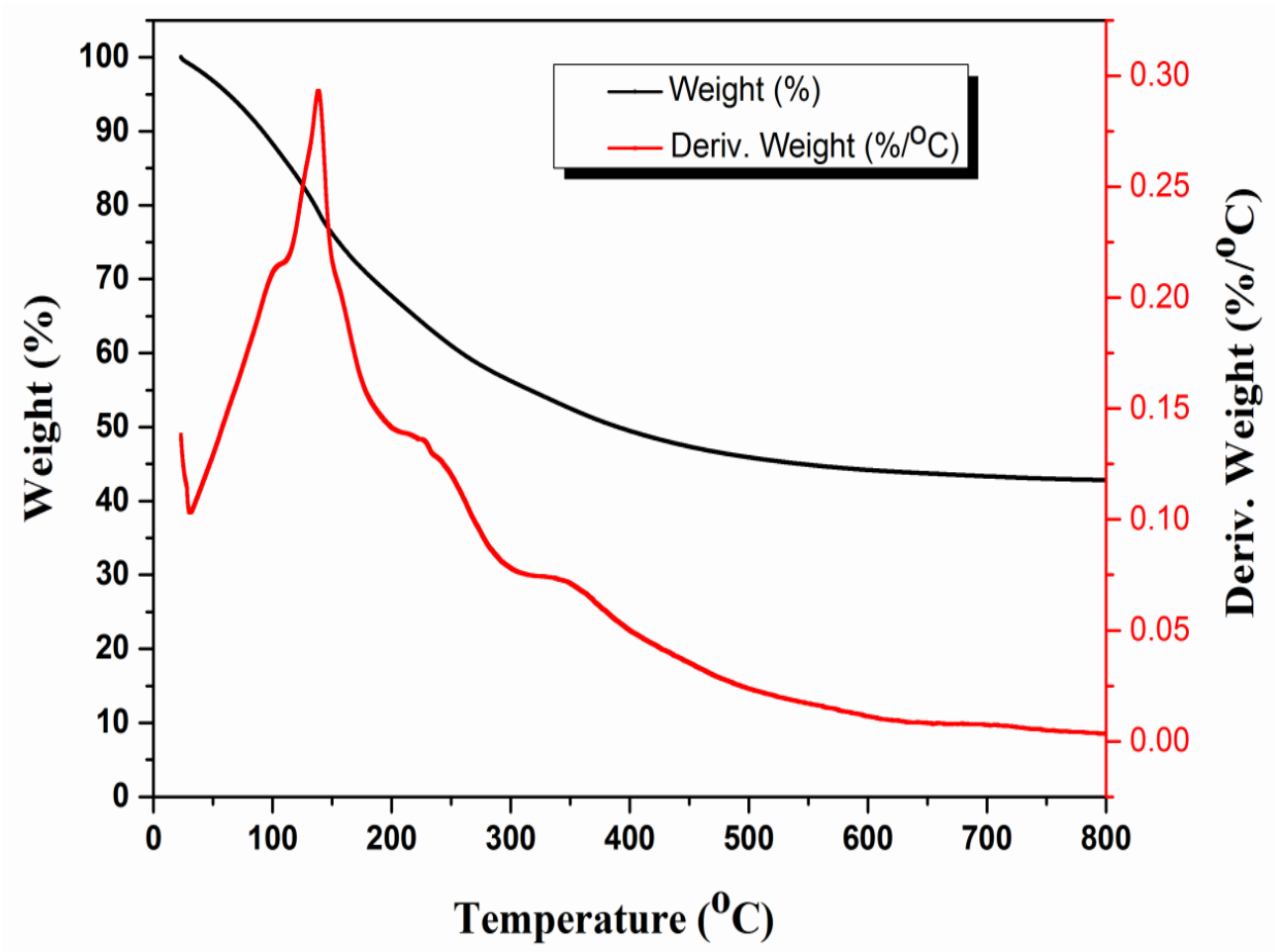

Figure 18: Thermogravimetric (TG) \& Drivative (DTG) analyses of EPSs extracted from A. clavatus.

Table 3: Technological TGA \& DTG characterization of EPSs extracted from A. clavatus.

\begin{tabular}{|c|c|c|c|c|c|c|c|c|c|c|}
\hline \multicolumn{3}{|c|}{ First stage } & \multicolumn{3}{|c|}{ Second stage } & \multicolumn{3}{|c|}{ Third stage } & \multirow{2}{*}{$\begin{array}{l}\text { Total Mass } \\
\text { Loss \% }\end{array}$} & \multirow[t]{2}{*}{ Residue \% } \\
\hline $\begin{array}{l}\text { initial } \\
\text { Temp, }{ }^{\circ} \mathrm{C}\end{array}$ & $\begin{array}{l}\text { Final } \\
\text { Temp, }{ }^{\circ} \mathrm{C}\end{array}$ & $\begin{array}{l}\text { DTG Max } \\
\text { Temp, }{ }^{\circ} \mathrm{C}\end{array}$ & $\begin{array}{l}\text { Initial } \\
\text { Temp, }{ }^{\circ} \mathrm{C}\end{array}$ & $\begin{array}{l}\text { Final } \\
\text { Temp, }{ }^{\circ} \mathrm{C}\end{array}$ & $\begin{array}{l}\text { DTG Max } \\
\text { Temp, }{ }^{\circ} \mathrm{C}\end{array}$ & $\begin{array}{l}\text { Initial } \\
\text { Temp, }{ }^{\circ} \mathrm{C}\end{array}$ & $\begin{array}{l}\text { Final } \\
\text { Temp, }{ }^{\circ} \mathrm{C}\end{array}$ & $\begin{array}{l}\text { DTG Max } \\
\text { Temp, }{ }^{\circ} \mathrm{C}\end{array}$ & & \\
\hline 50 & 200 & 139 & 205 & 300 & 240 & 300 & 800 & 355 & 57.21 & 42.79 \\
\hline
\end{tabular}

mass spectroscopy for EPSs indicated that polysaccharide (EPSs) was consists from $\alpha$-D-glucopyranosy6l unit $\left(\mathrm{C}_{12} \mathrm{H}_{22} \mathrm{O}_{11}\right)$ with molecular weight $342 \mathrm{~g} / \mathrm{moL}$.

\section{References}

1. Omoike AO, Chorover J (2004) Spectroscopic study of extracellular polymeric substances from Bacillus subtilis: Aqueous chemistry and adsorption effects. Biomacromolecules 5: 1219-1230.

2. Van Hullebusch ED, Zandvoort MH, Lens PLN (2003) Metal immobiliza-tion by biofilms: Mechanisms and analytical tools. Rev Environ Sci Bio/Technol 2: 9-33.

3. Jaroszuk MO, Wilkolazka AJ, Scisel JJ, et al. (2015) Extracellular polysaccharides from Ascomycota and Basidiomycota: Production conditions, biochemical characteristics, and biological properties. World J Microbiol Biotechnol 31: 1823-1844.

4. Mathur V, Mathur NK (2006) Microbial polysaccharides based food hydrocolloid additives. Sci Tech Enterpre 1-10.

5. Shu Ch, Lung M (2004) Effect of $\mathrm{pH}$ on the production and molecular weight distribution of exopolysaccharide by Antrodia camphoratain batch cultures. Process Biochem 39: 931-937.

6. Olsson PA, Thingstrup I, Jakobsen I, et al. (1999) Estimation of the biomass of arbuscular mycorrhizal fungi in a linseed field. Soil Biol Biochem 31: 1879-1887.
7. Donot F, Fontana A, Baccou JC, et al. (2012) Microbial exopolysaccharides: Main examples of synthesis, excretion, genetics and extraction. Carbohydr Polym 87: 951-962.

8. Mahapatra S, Banerjee D (2013) Fungal exopolisaccharide: Production, composition and applications. Microbiol Insights 6: 1-16.

9. Zhou LB, Chen B (2011) Bioactivities of water-soluble polysaccharides from Jison-grong mushroom: Anti-breast carcinoma cell and antioxidant potential. Int J Biol Macromol 48: 1-4.

10. Ma Z, Cui F, Gao X, et al. (2015) Purification, characterization, antioxidant activity and anti-aging of exopolysaccharides by Flammulina velutipesSF-06. Antonie Van Leeuwenhoek 107: 7382.

11. Dubois M, Gilles KA, Hamilton JK, et al. (1956) Colorimetric method for determination of sugars and related substances. Anal Chem 28: 350-356.

12. Miller GL (1972) Estimation of reducing sugar by di-nitrosalicyclic acid method. Anl Chem 31-42.

13. Lowry OH, Rosehmugh NJ, Farr AL, et al. (1951) Protein measurement with the Folin phenol reagent. J Biol Chem 193: 265-275.

14. Mostafa H (2006) Zytgomycetes. Fungi of Egypt AUMC descriptions NO. 1. Assiut university Mycological Center (AUMC), Assiut, Egypt. 
15. Moubasher A (1993) Soil fungi in Qatar and other arab countries. Published by the center for scientific and applied research, Univ. of Qatar, Doha, Qatar.

16. Di Hsu K, Wu SP, Lin SP, et al. (2017) Enhanced active extracellular polysaccharide production from Ganoderma formosanum using computational modeling. J Food Drug Anal 25: 804-811.

17. Peiqin LI, Liang Xu, Yan Mou, et al. (2012) Medium optimization for exopolysaccharide production in liquid culture of endophytic fungus Berkleasmium sp. Int J Mol Sci 13: 11411-11426.

18. Abou Zied AM, Eman HF, Abd El-Zaher HAH, et al. (2017) Exopolysaccharides production and characterization from marine-derived penicillium commune kp942881.1 with some medical potential applications. Egyptian Journal of Botany 17-30.

19. Xiao JH, Chen DX, Wan WH, et al. (2006) Enhanced simultaneous production of mycelia and intracellular polysaccharide in submerged cultivation of Cordyceps jiangxiensis using desirability functions. Process Biochemistry 41: 1887-1893.

20. Nehad EA, El-Shamy AR (2010) Physiological studies on the production of exopolysaccharide by Fungi Agric. Biol JN Am 1: 1303-1308.

21. Delattre C, Laroche C, Michaud P (2015) Production of microbial and fungal polysaacarides. Advances in Fermentation Technology 483-522.

22. Lee JH, Park YH (2001) Optimal production of curdlan by Agrobacterium sp. with feedback inferential control of optimal pH profile. Biotechnol Lett 23: 525-530.

23. Sinha J, Bae JT, Park JP, et al. (2001) Changes in morphology of Paecilomyces japonica and their effect on broth rheology during production of exo-biopolymers, Applied Microbial. Biotechnology 56: 88-92.

24. Kim SW, Hwang HJ, Xu CP, et al. (2003) Effect of aeration and agitation on the production of mycelial biomass and exopolysaccharides in an enthomopathogenic fungus Paecilomyces sinclairii. Lett Appl Microbiol 36: 321-326.

25. Chen Y, Mao W, Wang J, et al. (2013) Preparation and structural elucidation of a glucomannogalactan from marine fungus Penicillium commune. Carbohydr Polym 97: 293-299.

26. Yun Y, Han S, Lee S, et al. (2003) Anti-diabetic effects of CCCA, CMESS, and cordycepin from Cordyceps militaris and the immune responses in streptozotocin-induced diabetic mice. Nat Prod Sci 9: 291-298.

27. Osman M, Ahmed W, Hussein F, et al. (2014) Endopolysaccharides production and growth of Flammulina velutipes 6 under Submerged Conditions. J Chem Bio Phy Sci Sec B 4: 3350-3366.

28. Sharmila K, Alagarsamy K, Thillaimaharani KL, et al. (2014) Production and characterization of exopolysaccharides (EPS) from mangrove filamentous fungus, Syncephalastrum sp. African Journal of Microbiology Research 8: 2155-2161.

29. Lin J, Harichund C (2011) Isolation and characterization of heavy metal removing bacterial bioflocculants. Afr J Microbiol Res 5: 599-607.

30. Zhang J, Wang R, Jiang P, et al. (2002) Production of an exopolysaccharide bioflocculant by Sorangium cellulosum. Lett Appl Microbiol 34: 178-181.

31. Kwon G, Moon S, Hong S, et al. (1996) A novel flocculant biopolymer produced by Pestalotiopsis sp. KCTC-8637P. Biotechnol Lett 18: 1459-1464.

32. Zhang JJ, Q Zhang, J Wang, et al. (2009) Analysis of the monosaccharide composition of fucoidan by precolumn derivation HPLC. Chinese J Oceanol Limnol 27: 578-582.

33. Fengel D, Wegener G (1979) Hydrolysis of polysaccharides with trifluoroacetic acid and its application to rapid wood and pulp analysis. Advances in Chemistry 181: 145-158.

34. Ye M, Chen W, Qiu T, et al. (2012) Structural characterization and anti-ageing activity of extracellular polysaccharide from a strain of Lachnum sp. Food Chem 132: 338-343.

35. Yang L, LM Zhang (2009) Chemical structural and chain conformational characterization of some bioactive polysaccharides isolated from natural sources. Carbohydr Polym 76: 349-361.

36. Jiang Y, Cole BR (2005) Oligosaccharide analysis using anion attachment in negative mode electrospray. J Am Soc Mass Spectrom 16: 60-70.

37. Maleknia DS, Johnson R (2011) Mass spectrometry of amino acids and proteins 1-50.

38. Postulkova H, Chamradova I, Pavlinak D, et al. (2017) Study of effects and conditions on the solubility of natural polysaccharide gum karaya. Food Hydrocolloids 67: 148-156.

DOI: $10.36959 / 742 / 219$

Copyright: (c) 2019 Hussien SS. This is an open-access article distributed under the terms of the Creative Commons Attribution License, which permits unrestricted use, distribution, and reproduction in any medium, provided the original author and source are credited. 